\title{
Effects of anthropogenic land-subsidence on inundation dynamics: the case study of Ravenna, Italy
}

\author{
Francesca Carisi, Alessio Domeneghetti, and Attilio Castellarin \\ School of Civil, Chemical, Environmental and Materials Engineering, DICAM, \\ University of Bologna, Bologna, Italy \\ Correspondence to: Francesca Carisi (francesca.carisi@unibo.it) \\ Published: 12 May 2016
}

\begin{abstract}
Can differential land-subsidence significantly alter river flooding dynamics, and thus flood risk in flood prone areas? Many studies show how the lowering of the coastal areas is closely related to an increase in the flood-hazard due to more important tidal flooding and see level rise. The literature on the relationship between differential land-subsidence and possible alterations to riverine flood-hazard of inland areas is still sparse, although several geographical areas characterized by significant land-subsidence rates during the last 50 years experienced intensification in both inundation magnitude and frequency. We investigate the possible impact of a significant differential ground lowering on flood hazard over a $77 \mathrm{~km}^{2}$ area around the city of Ravenna, in Italy. The rate of land-subsidence in the study area, naturally in the order of a few mm year ${ }^{-1}$, dramatically increased up to $110 \mathrm{~mm}_{\text {year }}{ }^{-1}$ after World War II, primarily due to groundwater pumping and gas production platforms. The result was a cumulative drop that locally exceeds $1.5 \mathrm{~m}$. Using a recent digital elevation model $(\mathrm{res} .5 \mathrm{~m})$ and literature data on land-subsidence, we constructed a ground elevation model over the study area in 1897 and we characterized either the current and the historical DEM with or without road embankments and land-reclamation channels in their current configuration. We then considered these four different topographic models and a twodimensional hydrodynamic model to simulate and compare the inundation dynamics associated with a levee failure scenario along embankment system of the river Montone, which flows eastward in the southern portion of the study area. For each topographic model, we quantified the flood hazard in terms of maximum water depth $(h)$ and we compared the actual effects on flood-hazard dynamics of differential land-subsidence relative to those associated with other man-made topographic alterations, which resulted to be much more significant.
\end{abstract}

\section{Introduction}

As clearly highlighted in the recent literature, the study of hydrological processes cannot neglect the effect of anthropogenic impacts on the territory (e.g. Montanari et al., 2014 and many writings in the context of the new science of sociohydrology, proposed by Sivapalan et al., 2012; Di Baldassarre et al., 2013 and references therein). Human and water systems are in fact closely related, so that various authors demonstrated how flood-risk evolution and the increasing of potential damages during extreme flood events are often linked to the strong land-anthropization, rather than to climate change (see e.g. Domeneghetti et al., 2015; Bouwer et al., 2010). Our study considers the human-induced landsubsidence due to the pumping of underground fluids in densely populated areas. This phenomenon has been documented, especially in the last half of the XX century, in different parts of the world, such as in Japan (see e.g. Daito and Galloway, 2015), Mexico (Toscana and Campos, 2010), Thailand (Phien-wej et al., 2006) and Bangladesh (Brown and Nicholls, 2015; Howladar and Hasan, 2014). Literature on the effects of land-subsidence in coastal areas is rich, see e.g. the effects of salt-water intrusion (see e.g. Schmidt, 2015) and the decrease of the coastal floods return period (see e.g. Yin et al., 2013), while the dynamics of hydraulic risk in rivers flood-prone areas is still poorly investigated and understood. The aim of our study is to understand whether and in to what extent the human-induced land-subsidence can change the riverine potential flooding. To investigate these aspects 

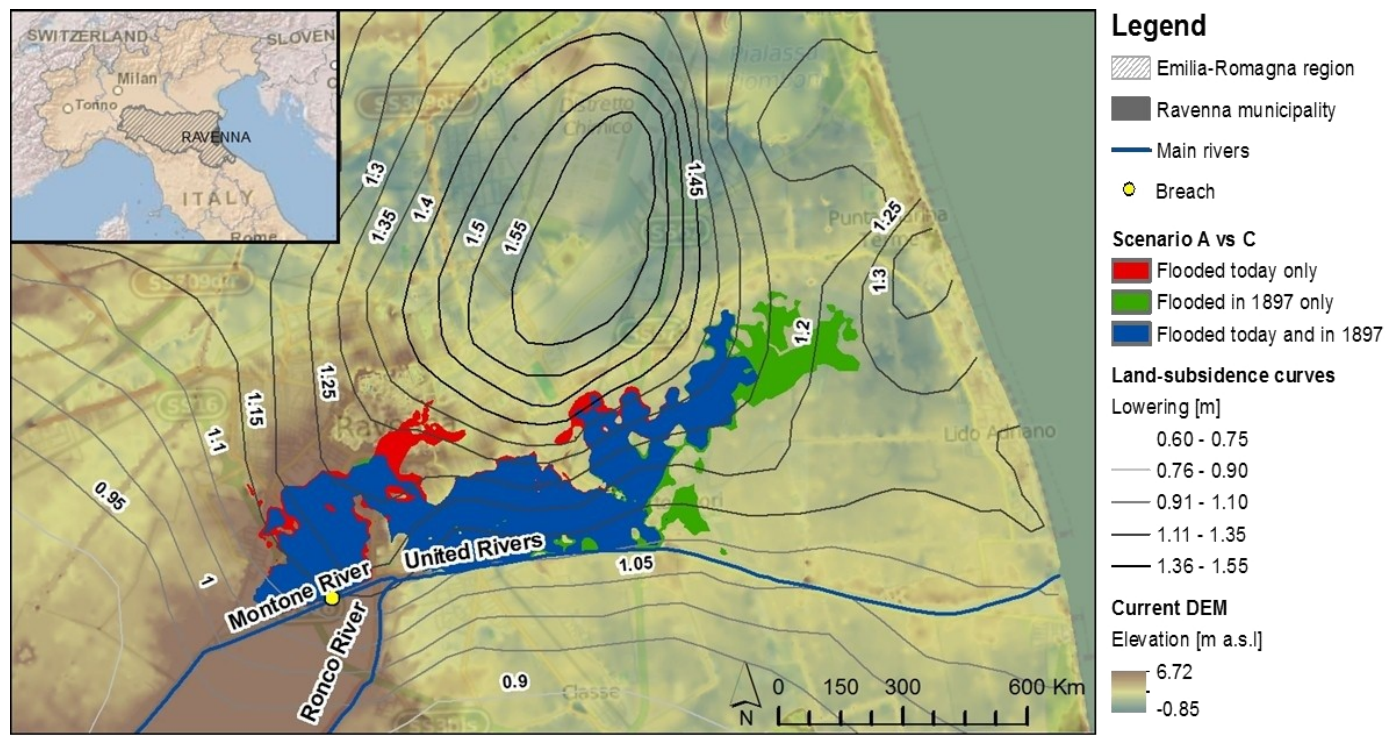

Figure 1. Study area and union of flooded area in scenarios A (current DEM without infrastructures) and C (1897's DEM without infrastructures): blue indicates areas flooded in both scenarios, red and green areas are flooded exclusively in Scenario A and C, respectively.

we focus on the most resounding case of anthropogenic landsubsidence in Italy, which is the area near the city of Ravenna (Northern Italy; see Fig. 1). Here the monitoring of ground elevation by traditional as well as more advanced techniques (see e.g. Bitelli et al., 2000) showed that the land-subsidence rate experienced a sudden acceleration in the aftermath of World War II due to an intense water and gas extraction from underground (Gambolati et al., 1991; Carminati et al., 2002). The latter produced more than $1.5 \mathrm{~m}$ cumulative lowering near the historical city centre of Ravenna (see Fig. 1). Ravenna is surrounded and crossed by natural streams that are characterized by artificial embankment systems protecting the city from frequent flooding. In case of extreme events or levee failures (i.e. what is usually identified as "residual flood risk"; see e.g. Castellarin et al., 2011; Di Baldassarre et al., 2009b) it would lead to higher damages, than those which would occur if rivers could expand freely in the surrounding plain. This paradox is called "levee effect" and describes the frequent phenomenon in which the flood control systems encourages urbanization in areas that are even closer to rivers (Tobin, 1995). We selected this study area because of its location (only a few kilometers from the coast) and all factors described above. We investigate the effects of landsubsidence and man-made infrastructures in the study area on the flood dynamics that is expected in case of a leveefailure in the proximity of the urban area of Ravenna. The analyses are performed by adopting fully-2-D models which consider different topographic scenarios.

\section{Study area}

The study area consists of a $77 \mathrm{~km}^{2}$ area around the city of Ravenna, in the Emilia-Romagna region (Northern Italy; Fig. 1). With a municipal area of $653 \mathrm{~km}^{2}$ and a population of 160000 inhabitants, the city is located few kilometers away from the Adriatic coast. Ravenna is one of the oldest Italian towns, presumably founded in the eight century BC.

Although an inland city, Ravenna is directly connected to the Adriatic Sea by the Candiano Canal and is crossed by the Montone River (United Rivers after the confluence of the Ronco River). High population density, as well as a complex network of road infrastructures characterize the study area.

Like many other coastal lowlands and deltaic plains, the eastern Po plain and in particular the district of Ravenna lye on a subsiding sedimentary basin, where extremely significant changes in terms of ground elevation occurred over centuries relative to the Adriatic mean sea level. The landsubsidence rate in the area, naturally in the order of few mm year ${ }^{-1}$, increased enormously after World War II. The main driver is believed to be the increase in the extraction of deep non-rechargeable groundwater, related to the growth of the economic activities in the Po Basin. The close relationship between groundwater pumping and land-subsidence was confirmed, among the other studies, by the lowering of subsidence rate experienced after a strong reduction of groundwater withdrawal (see Carminati et al., 2002 and references therein). Other studies identified the exploitation of several on-shore and off-shore deep gas reservoirs in the Ravenna area as an additional factor that contributed to the growing of land-subsidence rate up to some centimeters per year (see e.g. Gambolati et al., 1991). In 2005, Teatini et al. (2005) pro- 
vided a detailed georeferenced map of land-subsidence in the eastern Po River plain over the period 1897-2002, based on the main levelling surveys databases available in the Ravenna area for the last century (IGM, Ravenna Reclamation Authority, Geological Service of the Ravenna Municipality, ARPA and ENI-E\&P).

Although land-subsidence rate before the 1950s could be assumed to be almost constant (Teatini et al., 2005), we chose this map as the starting point to perform our study, therefore investigating the possible role of land-subsidence on flood-hazard evolution in the period 1897-2002. As shown in Fig. 1, land-subsidence drops in the last fifty years are larger than $1 \mathrm{~m}$ over more than one third of the study area, with peaks higher than $1.5 \mathrm{~m}$ over an area of $10 \mathrm{~km}^{2}$ between the historical center and the coastline. Apart from the significant ground lowering, one must also consider the potential negative effects of differential subsidence occurred in the study area: as an example, in the northeast part of the study area the topographic lowering passes from 1.55 to $1.25 \mathrm{~m}$, with a $\approx 0.30 \%$ o horizontal gradient.

\section{Topography of the study area: current and reconstructed conditions}

The current topography of the study area is described by a $5 \mathrm{~m}$ Digital Elevation Model (DEM), available as a GIS Service and provided by the cartographic offices of the EmiliaRomagna for the entire region (Fig. 1).

With the aim of comparing inundation dynamics under current and historical topographic conditions, we reconstructed the ground elevations before the land-subsidence occurred during last decades. In particular, the cumulative landsubsidence contour lines between 1897 and 2002 described in Teatini et al. (2005) were used for back-warping the current $5 \mathrm{~m}$ DEM obtaining a historical DEM describing ground elevations in 1897. This procedure is based on the assumption that between 2002 and today no significant change in ground elevations occurred.

The area to the Northeast of the center of Ravenna suffered the greatest drop (ca. $155 \mathrm{~cm}$ ) and for this reason it is raised the most in the back-warped DEM. The area located approximately $4 \mathrm{~km}$ from the city of Ravenna to the South-West experienced the opposite situation, so the ground elevation was raised about $80 \mathrm{~cm}$ only, when reconstructing the historical morphology.

The influence of main infrastructures on the flooding dynamics are considered by modifying the discontinuities elevation according to the real topographic characteristics of the elements: we lift the railways elevation by $1 \mathrm{~m}$ and we lower the greater channel elevation by $1.5 \mathrm{~m}$.

\section{2-D numerical model}

We perform our study by means of the fully-2-D hydrodynamic model TELEMAC-2-D, which solves the 2-D shallow water Saint-Venant equations using the finite-element method within a computational mesh of triangular elements (see Galland et al., 1991; Hervouet and Van Haren, 1996). TELEMAC-2-D was adopted in previous studies and similar geographical context, proving to accurately reproduce the real flooding dynamics in a complex floodplain topography (e.g. Di Baldassarre et al., 2009a). One of the advantages of TELEMAC-2-D as finite elements model is the possibility to use structured or non-structured computational meshes. These last, in particular, provide a densification of the triangular elements at certain critical points and allow to better describe the topographical discontinuity that influences the inundation process, such as levees, road and railway embankments (Domeneghetti, 2014; Di Baldassarre et al., 2009b). For this preliminary study, we refer to a non-structured triangular mesh densified at the major discontinuities that can influence our process of flooding, such as boundaries, channels, roads and railways.

As far as what the Manning's coefficient is concerned, we rely on land-use maps available for the Emilia-Romagna region and retrieved from aerial imagery available for 2008 (AGEA-2008), classified on the base of the standardized classes aggregation adopted by the CORINE (COoRdinated INformation on the Environment) project (EEA, 2009). For each land-use class in the study area we use a different value of the Manning coefficient according to the indications provided in the literature (see e.g. Vorogushyn, 2008; Domeneghetti et al., 2013).

TELEMAC-2-D is used to simulate the inundation dynamics in the area of interest, assuming the formation of a single breach in the left embankment of the Montone River, near the confluence with the Ronco River (see Fig. 1). The breach, which is about $120 \mathrm{~m}$ wide and $4.5 \mathrm{~m}$ deep (from the embankment crest to the elevation of the ground), is assumed to develop instantaneously, triggered by a hypothetical embankment overtopping. The dimension of the breach is typical for embankment systems similar to the one of the River Montone (see e.g. breaches in the Serchio River, December 2009).

The overflowing discharge at the breach has been calculated by referring to a quasi-2-D model of the MontoneRonco river system (see Castellarin et al., 2011 for an analogous modelling scheme) adopted for the simulation of a 30years return period flood wave (AdB-RR, 2011). The overflowing discharges simulated at the breach by the quasi-2-D model are used in our study as boundary conditions for the 2-D model in order to simulate the inundation dynamics associated with 1897's and the current topographic conditions.

In order to assess the role of land-subsidence compared with man-made topographic alterations in river flood-hazard, independently by all other factors, the simulations are performed by considering the bathymetry evolution in the pe- 

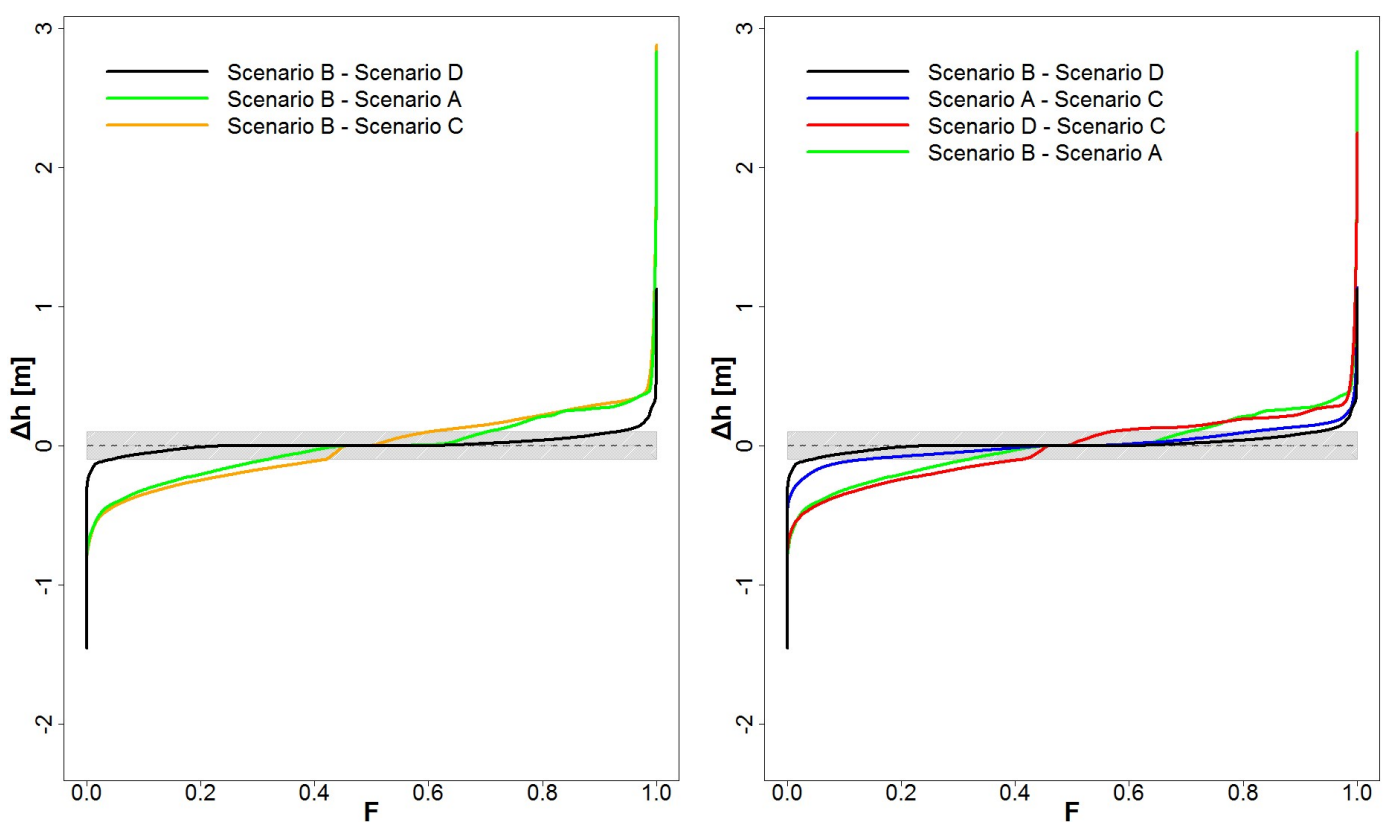

Figure 2. Cumulative distribution function of water depth differences between scenarios, $\Delta h$ (i.e. differences between water depths simulated for two Scenarios X and Y); "Scenario X - Scenario Y" indicates $\Delta h$ values computed as water depths simulated for Scenario X minus water depths simulated for Scenario Y; grey dashed areas highlight non significant $\Delta h$ values (i.e. absolute values lower than $10 \mathrm{~cm}$ ).

riod of interest (1897-2002). We consider four resulting topographic conditions:

- Scenario A: current morphology without infrastructures;

- Scenario B: current morphology with main infrastructures (i.e. minor channels, railways, roads, etc.)

- Scenario C: 1897 reconstructed morphology (i.e. backwarped DEM) without infrastructures

- Scenario D: 1897 reconstructed morphology with main infrastructures.

\section{Results and discussion}

In order to describe the flooding dynamics in the area of interest, we focus on the maximum water depth $(h)$ resulting from the simulations for all time steps and for each scenario (A, B, C and D).

Figure 1 shows an example of the results in terms of significantly (water depths $h \geq 10 \mathrm{~cm}$ ) flooded areas in two different scenarios: A (current DEM) and C (1897 reconstructed DEM). The blue areas indicate the portion flooded in both topographic scenarios, while areas that are either flooded for 1897 or current are reported in green and red, respectively. Although the extent of the blue area is much larger than the green and red ones, it is evident that in the present scenario the flood-risk affects mainly the urban area of the city of Ravenna, while in 1897 the rural areas in the Eastern side were mostly impacted by inundation. The cause, as expected, is the ground lowering due to the land-subsidence, which had its peak in the historical city center.

Using as reference area the union of the significantly flooded areas in all four scenarios (representing the areas with simulated water depths $h \geq 10 \mathrm{~cm}$ at least in one scenario), we computed the differences of the water depths $(\Delta h)$ for all scenarios pairs. The comparison of different scenarios are shown in terms of the exceedance probability $(F)$ of a certain difference of water depth $(\Delta h)$ (see Fig. 2, left and right panels).

Very flat lines around $\Delta h=0$ in Fig. 2 indicate that the two compared scenarios are very similar in terms of maximum simulated $h$. Lines that deviate from 0 indicate scenarios whose simulations provided significantly different simulated maximum $h$.

A first comparison, shown in the left panel of Fig. 2, is performed by considering Scenario B as reference scenario, as it represents the situation closer to reality (current DEM and schematization of major infrastructures). Water depths in any other scenarios (A, C and D) are therefore subtracted from water depths in Scenario B, in order to understand which scenario is more deviated from the real one. The black line in Fig. 2 (left panel) represents the differences between $h$ in Scenarios B and D (1897's DEM with major infrastructures); the green line shows the comparison between Scenarios B and A (current DEM without major infrastructures); the orange line represents the differences between Scenarios B and C, the latter considering the 1897's topography and 
Table 1. Comparison of different scenarios, percentage of flooded areas with significant (i.e. absolute values larger than $10 \mathrm{~cm}$ ) $\Delta h$ (i.e. differences between water depths simulated for two Scenarios $\mathrm{X}$ and $\mathrm{Y}$ ); " $\mathrm{X}-\mathrm{Y}$ ” indicates $\Delta h$ values computed as water depths simulated for Scenario $\mathrm{X}$ minus water depths simulated for Scenario Y.

\begin{tabular}{lllll}
\hline & Scenario A & Scenario B & Scenario C & Scenario D \\
\hline Scenario A & & $61 \%$ & $32 \%$ & $62 \%$ \\
Scenario B & B - A & & $82 \%$ & $11 \%$ \\
Scenario C & A - C & B - C & & $84 \%$ \\
Scenario D & D - A & B - D & D - C & \\
\hline
\end{tabular}

the absence of major infrastructures. The results demonstrate that taking into account the land-subsidence in the study area leads to maximum water depths that are quite similar to those that result from the simulation with the current DEM (black line). Only $11 \%$ of the reference area experiences significant $\Delta h$, i.e. larger than $\pm 10 \mathrm{~cm}$ (in $4 \%$ of the flooded extent, maximum water depths in Scenario B are lower than in Scenario $\mathrm{D}$ and in $7 \%$ of the area, the opposite occurs), while in the remaining $89 \%$ the differences can be neglected (i.e. $\Delta h$ lower than $\pm 10 \mathrm{~cm}$, dashed grey areas in Fig. 2, left panel). As far as the comparison between Scenarios B and A is concerned (green line), the percentage of flooded area with negligible $\Delta h$ (lower than $\pm 10 \mathrm{~cm}$ ) is equal to $39 \%$, while in the remaining $61 \%$ of the extent the differences are more significant. On the basis of these results, it is rather evident that the effects of differential land-subsidence on flood risk in the study area are negligible if compared to the impacts of major infrastructures. The comparison between Scenarios $\mathrm{B}$ and $\mathrm{C}$ (orange line) shows $18 \%$ of the flooded areas with negligible $\Delta h$ and $82 \%$ with significant differences in terms of maximum water depths. These values show that Scenarios $\mathrm{B}$ and $\mathrm{C}$ are the most different ones, as expected, but the cumulative distribution function of $\Delta h$ in this comparison has a very similar trend to that given by the comparison between Scenarios B and A.

A second graph, shown in the right panel of Fig. 2, compares differences in terms of maximum $h$ due to the ground drop caused by land-subsidence (starting either from a simple configuration, Scenarios A-C, and by configurations in which the infrastructure are considered: Scenarios B-D, respectively) and the differences due to the modification of major discontinuities (starting either from the current configuration, Scenarios B-A, and from the 1897's configuration Scenarios D-C).

The results in terms of percentages of the reference area with significant $\Delta h$ are presented in Table 1 and confirm that the change in elevation associated with major infrastructures is more important than land-subsidence when simulating the flooding dynamics.

\section{Conclusions}

Our study assesses the effects of anthropogenic landsubsidence on river flood hazard in the geographical area close to the city of Ravenna, which was affected by an important ground drop in the last century (i.e. more than $1.5 \mathrm{~m}$ in the historical city center). The analysis shows that large and rapid differential land-subsidence does not seem to lead to significant alterations to the flooding hazard (if we only consider the maximum water depth as local indicator).

Comparing differences arising from the comparison between simulation in the current configuration and in presence of ground lowering with those caused by the effects of major infrastructures, we can see that human-induced drivers, like construction of canals and road embankments, has an higher impact on flood-hazard than anthropogenic land-subsidence.

In addition, the study further shows the importance of an accurate identification of specific topographic data that have to be considered in the modelling exercise, which should represent the best compromise between precision, maximum expected accuracy and computational efficiency (Dottori et al., 2013).

Acknowledgements. The study is part of the research activities carried out by the working group: Anthropogenic and Climatic Controls on WateR AvailabilitY (ACCuRAcY) of Panta Rhei - Everything Flows: Change in Hydrology and Society (IAHS Scientific Decade 2013-2022).

\section{References}

AdB-RR: Piano Stralcio per il Rischio Idrogeologico - Variante al Titolo II "Assetto della rete idrografica", 2011.

Bitelli, G., Bonsignore, F., and Unguendoli, M.: Levelling and GPS networks to monitor ground subsidence in the Southern Po Valley, J. Geodynam., 30, 355-369, 2000.

Bouwer, L. M., Bubeck, P., and Aerts, J. C. J. H.: Changes in future flood risk due to climate and development in a Dutch polder area, Global Environ. Change, 20, 463-471, 2010.

Brown, S. and Nicholls, R. J,: Subsidence and human influences in mega deltas: The case of the Ganges-Brahmaputra-Meghna, Sci. Total Environ., 527-528, 362-374, 2015.

Carminati, E. and Martinelli, G.: Subsidence rates in the Po Plain, northern Italy: the relative impact of natural and anthropogenic causation, Eng. Geol., 66, 241-255, 2002.

Castellarin, A., Domeneghetti, A., and Brath, A.. Identifying robust large-scale flood risk mitigation strategies: A quasi-2D hydraulic model as a tool for the Po river, Phys. Chem. Earth, 36, 299-308, 2011.

Daito, K. and Galloway, D. L.: Preface: Prevention and mitigation of natural and anthoropogenic hazards due to land subsidence, Proc. IAHS, 372, 555-557, doi:10.5194/piahs-372-5552015, 2015.

Di Baldassarre, G., Castellarin, A., Montanari, A., and Brath, A.: Probability weighted hazard maps for comparing different flood 
risk management strategies: a case study, Nat. Hazards, 50, 479496, 2009a.

Di Baldassarre, G., Castellarin, A., and Brath, A.: Analysis of the effects of levee heightening on flood propagation: example of the River Po, Italy, Hydrol. Sci. J., 54, 1007-1017, 2009 b.

Di Baldassarre, G., Kooy, M., Kemerink, J. S., and Brandimarte, L.: Towards understanding the dynamic behaviour of floodplains as human-water systems, Hydrol. Earth Syst. Sci., 17, 3235-3244, doi:10.5194/hess-17-3235-2013, 2013.

Domeneghetti, A.: Effects of minor drainage networks on flood hazard evaluation, Proc. IAHS, 364, 192-197, doi:10.5194/piahs364-192-2014, 2014.

Domeneghetti, A., Vorogushyn, S., Castellarin, A., Merz, B., and Brath, A.: Probabilistic flood hazard mapping: effects of uncertain boundary conditions, Hydrol. Earth Syst. Sci., 17, 31273140, doi:10.5194/hess-17-3127-2013, 2013.

Domeneghetti A., Carisi, F., Castellarin, A., and Brath, A.: Evolution of flood risk over large areas: Quantitative assessment for the Po river, J. Hydrol., 527, 809-823, 2015.

Dottori, F., Di Baldassarre, G., and Todini, E.: Detailed data is welcome, but with a pinch of salt: Accuracy, precision, and uncertainty in flood inundation modeling, Water Resour. Res., 49, 6079-6085, 2013.

European Environment Agency (EEA): CORINE Land Cover 2006 (CLC2006) 100 m, [112/2009], Denmark, Copenhagen, 2009.

Galland, J. C., Goutal, N., and Hervouet, J. M.: TELEMAC: a new numerical model for solving shallow water equations, Adv. Water Resour., 14, 38-148, 1991.

Gambolati, G., Ricceri, G., Bertoni, W., Brighenti, G., and Vuillermin, E.: Mathematical simulation of the subsidence of Ravenna, Water Resour. Res., 27, 2899-2918, 1991.

Hervouet, J. M. and Van Haren, L.: Recent advances in numerical methods for fluid flows, in: Floodplain Processes, John Wiley \& Sons, Inc., Chichester, UK, 183-214, 1996.
Howladar, M. F. and Hasan, K.: A study on the development of subsidence due to the extraction of 1203 slice with its associated factors around Barapukuria underground coal mining industrial area, Dinajpur, Bangladesh, Environ. Earth Sci., 72, 3699-3713, 2014.

Montanari, A., Ceola, S., and Baratti, E.: Panta Rhei: an evolving scientific decade with a focus on water systems, Proc. IAHS, 364, 279-284, doi:10.5194/piahs-364-279-2014, 2014.

Phien-wej, N., Giao, P. H., and Nutalaya, P.: Land subsidence in Bangkok, Thailand, Eng. Geol., 82, 187-201, 2006.

Teatini, P., Ferronato, M., Gambolati, G., Bertoni, W., and Gonella, M.: A century of land subsidence in Ravenna, Italy, Environ. Geol., 47, 831-846, 2005.

Tobin, G. A.: The levee love arrair: a stormy relationship?, J. Am. Water Resour. As., 31, 359-367, 1995.

Toscana, A. and Campos, M. M.: Environmental and social effects derived from groundwater extraction in Tláhuac and Valle-deChalco-Solidaridad, Metropolitan Area of Mexico City, Proc. IAHS, 414-418, 2010.

Schmidt, C. W.: Delta subsidence - An imminent threat to coastal populations, Environ. Health Persp., 123, 204-209, 2015.

Sivapalan, M., Savenjie, H. G., and Blöschl, G.: Socio-hydrology: A new science of people and water, Hydrol. Proc., 26, 1270-1276, 2012.

Vorogushyn, S.: Analysis of flood hazard under consideration of dike breaches, Dissertation, Universität Potsdam, Potsdam, Germany, 2008.

Yin J., Yu, D., Yin, Z., Wang, J., and Xu, S.: Modelling the combined impacts of sea-level rise and land subsidence on storm tides induced flooding of the Huangpu River in Shanghai, China, Clim. Change, 119, 919-932, 2013. 